\title{
Scharioth Macula Lens: A new intraocular implant for low-vision patients with stabilized maculopathy- first experience
}

\author{
Jana Nekolova ${ }^{a}$, Pavel Rozsivala ${ }^{a}$, Martin Sin ${ }^{\mathrm{b}}$, Nada Jiraskova $^{\mathrm{a}}$
}

\begin{abstract}
Aims. To present the initial results of Scharioth Macula Lens (SML) implantation. The SML is a new add-on intraocular lens designed to increase uncorrected near visual acuity (UCVA) in patients with stabilized maculopathy.

Methods. Eight patients were included in the study. All met the indication criteria before SML implantation. An SML was implanted in the better seeing eye. Near and distance visual acuity were tested. Possible complications and patient complaints were recorded and patients were asked about their quality of vision after SML implantation. The examination was carried out on day 1, 1 week, 1, 3 and 6 months after surgery.

Results. Six-month-results are presented. Apart from one, all patients with the SML had good near visual acuity at a recommended reading distance of $15 \mathrm{~cm}$. Preoperatively, the mean (min-max) near UCVA was J13 (J8-J16), mean distance BCVA was 0.27. Postoperatively, the best results were after 1 month - near UCVA was J2.5 (J1-J7), distance BCVA was 0.26 . Three months after surgery, this decreased to $\mathrm{J} 4.5(\mathrm{~J} 1 \mathrm{~J} 8 \mathrm{~J})$; distance VA remained 0.25 . Six months postoperatively near vision was $\mathrm{J} 4 \mathrm{~J}(\mathrm{~J}-\mathrm{J} 8$ ) and distance VA was unchanged. Patients reported problems with reading speed and reading distance. Daily exercise improved their reading ability. One patient converted to wet AMD 3 months post-implantation. Conclusion. The SML is a new hope for low-vision patients. It acts as a magnifier in the eye. It is a suitable method for increasing near visual acuity in patients with inactive maculopathy.
\end{abstract}

Key words: Scharioth Macula Lens, maculopathy, low-vision, near vision improvement

Received: December 11, 2016; Accepted: March 22, 2017; Available online: April 26, 2017

https://doi.org/10.5507/bp.2017.014

${ }^{a}$ Department of Ophthalmology, University Hospital in Hradec Kralove, Czech Republic

${ }^{b}$ Department of Ophtalmology, University Hospital Olomouc, Czech Republic

Corresponding author: Jana Nekolova, e-mail:jana.nekolova@fnhk.cz

\section{INTRODUCTION}

Macular pathology causes a significant amount of vision loss and increases vision-specific disability, decreases quality of life, and may even increase mortality

Macular degenerations and dystrophies often result in significant visual impairment which limits a patient's daily activities requiring good central vision, such as self-care, reading, recognizing facial features, driving, watching television, and other social activities ${ }^{1}$. Impaired vision is thus an important cause of depression and anxiety ${ }^{2}$. In the developed world, age-related macular degeneration (AMD), diabetic or myopic maculopathy, and maculopathy after retinal vein occlusion are the most common macular degenerations. Near vision testing is a sensitive indicator of the presence of macular disease. To help visually handicapped patients, there are several external magnifying low visual aids available on the market, which are based on either optical or electronical magnification. Many older visually impaired adults have difficulty in getting used to a new device and refuse to use them. Some disadvantages of external aids can be surpassed using intraocular implants $^{3,4}$.

The Scharioth Macula Lens (SML; A45SML) acts as a magnifier in the eye. It is a new one-piece foldable intraocular lens (IOL) made from a copolymer of hydrophilic and hydrophobic acrylic. The lens is implanted into the ciliary sulcus in addition to a primary IOL in the patient's pseudophakic eye. The lens is aspheric bifocal, with a 1.5 $\mathrm{mm}$ diameter central portion and an addition of +10 diopters (Fig. 1). The remaining optical zone is refractory neutral, or the diopters of this zone may be individually adapted. The lens is available in clear or yellow versions. It has the Conformite Européenne mark and is patent pending 5 . Our initial clinical results from eyes implanted with the SML in patients with age-related macular degeneration are presented.

\section{MATERIALS AND METHODS}

This trial was conducted at the Department of Ophthalmology, University Hospital in Hradec Králové, Czech Republic, from January 2015. It was reviewed by the local ethics committee, all tenets of the Declaration of Helsinki were followed and all patients provided informed consent. Eight patients were included. All of the patients had met the indication criteria for implantation recommended by the inventor (prof. Scharioth, Recklinghausen, Germany) and manufacturer (Medicontur International, Geneva, Switzerland) before SML implantation: age eligible for the study over 55 years, best corrected distance visual acuity (BCVA) from 0.05 to 0.4 , stabilized maculopathy and a pseudophakic eye. According to the recom- 


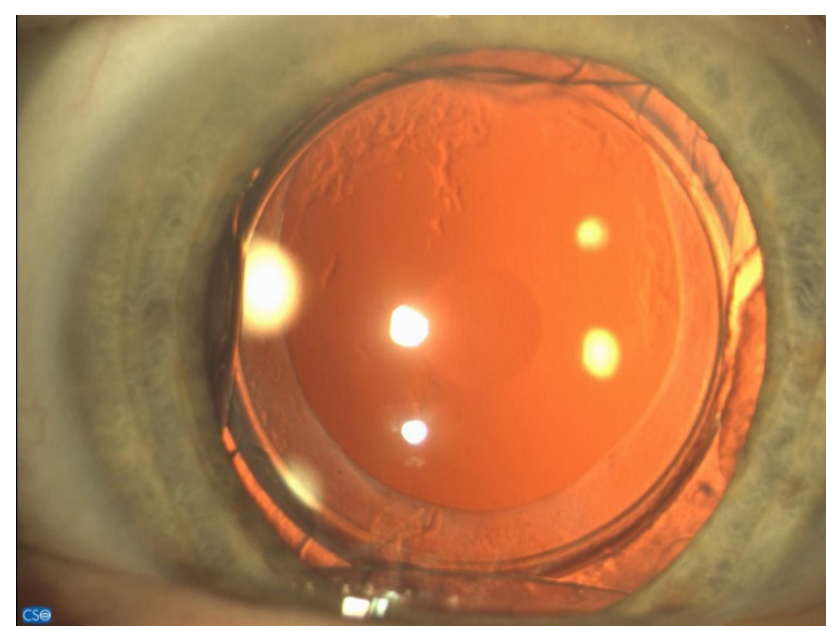

Fig. 1. Correct centration of Scharioth Macula Lens in the eye, haptics fixed in a sulcus, central part of +10 diopters on the visual axis, behind the SML there is an intraocular lens in the capsular bag.

mendations, we tested near vision with +6.0 diopters from a distance of $15 \mathrm{~cm}$ preoperatively, which is known to be equal to uncorrected VA postoperatively. The near VA was measured using the Jaeger chart, which is a card on which paragraphs of text are printed, with the text sizes increasing from $0.37 \mathrm{~mm}$ to $2.5 \mathrm{~mm}\left(\right.$ ref. $\left.^{6}\right)$. The card is held by a patient at a fixed distance from the eye depending on the Jaeger size being read. The smallest print that the patient can read determines their visual acuity. Patients eligible for the SML implantation had to reach a reasonable improvement of uncorrected VA; in our study the selected text size was Jaeger number 6 or better.

Exclusion criteria were active maculopathy, iris neovascularization or atrophy, photopic pupil size less than $2.5 \mathrm{~mm}$, severe zonulopathy, anterior chamber depth less than $2.8 \mathrm{~mm}$, narrow angle or severe eye pathology or previous retinal surgery.

The Scharioth Macula Lens was monocularly implanted in the better seeing eye. Surgery was performed by the same surgeon (P.R.). After pupil dilatation and topic anesthesia, an incision of $2.2 \mathrm{~mm}$ was made, the anterior chamber was filled with an Eyevisc ophthalmic viscosurgical device (OVD) and an add-on SML was placed in the cartridge. After implantation, proper positioning of the haptics in the ciliary sulcus and IOL centration were checked and finally the OVD was removed and the incisions were hydrated ${ }^{5}$. All of the patients were subjected to a standard postoperative regimen of a topical antibiotic for one week and a topical steroid for one month.

Following the implantation, all of the patients were advised to perform reading exercises every day. We provided them with instructions and training texts to facilitate the postoperative adaptation. They were advised to read without glasses or other external magnifiers at least twice a day for $10 \mathrm{~min}$ a session. They were instructed that sharp vision is achieved at a very near distance of 10-15 $\mathrm{cm}$ and all of the patients were asked to read from the largest to the smallest type they were comfortable with. High contrast reading materials were recommended at the beginning. Good lighting conditions and having a rest when tired were the other crucial recommendations.

At the baseline and 1 day, 1 week, 1, 3 and 6 months after surgery, the examination included an assessment of uncorrected and best corrected visual acuity at distance (ETDRS charts), visual acuity at a near tested Jaeger reading chart, non-contact intraocular pressure (IOP) measurement, fundus photography, optical coherence tomography, and clinical examination, after pupil dilatation.

While reading, a chart was held at a comfortable reading distance and this was measured and noted. Possible complications were recorded and patients were asked about the quality of their vision after SML implantation. Reading performance was tested and training was provided and, if necessary, improvement of reading technique was recommended.

\section{RESULTS}

The average (minimal-maximal) age of participants of this study was 79 years (73-85 years). There were 3 men and 5 women. All of the patients underwent cataract surgery approximately 7.5 years (2-15 years) before SML implantation.

All but one of the performed surgeries were uneventful. The Scharioth Macula Lens was implanted into the right eye four times and into the left eye four times. In patient No. 8 there was a problem with haptic damage during implantation, the tunnel was enlarged, the damaged Macula Lens was removed and replaced with a new SML and suture of incision was performed, all without any further complications or effect on postoperative recovery.

Apart from one, all of the patients with the SML acquired good near visual acuity at a recommended reading distance of $15 \mathrm{~cm}$. Preoperatively, the mean (min-max) near UCVA was J13 (J8-J16), with +6.0 diopters J2 (J1$\mathrm{J} 5)$ and the mean distance BCVA was $0.27(0.2-0.3)$. Postoperatively, the best results were after one month near UCVA was J2.5 (J1-J7), and the distance BCVA was $0.26(0.2-0.3)$. Three months after surgery, this decreased to J4.5 (J1-J8); distance VA remained at 0.25 (0.15-0.3). Six months postoperatively - near vision was J4 (J1-J8) and distance VA was unchanged at $0.24(0.2-0.3)$. Reading results are shown in the Table 1.

Postoperative recovery of all of the patients was rapid. No complaints about diplopia or glare were recorded. The patients reported problems with reading speed and reading distance. Daily reading exercises improved their reading ability, and patients emphasized the need for good light. The eye without the SML disturbed near vision in five of the patients and had to be covered during reading for a temporary period of two to four weeks postoperatively.

There was no difference between the mean preoperative and postoperative IOPs. Preoperatively, the mean IOP (minimum-maximum values) was $13 \mathrm{mmHg}$ (11-16 $\mathrm{mmHg}), 1$ day after surgery it was $13 \mathrm{mmHg}$ (8$15 \mathrm{mmHg})$, one week postoperativelly $14 \mathrm{mmHg}(8-21$ $\mathrm{mmHg})$, after one month it was $15 \mathrm{mmHg}(9-23 \mathrm{mmHg})$, 
Table 1. Near visual acuity before and after SML implantation (measured with the Jaeger chart), uncorrected postoperatively.

\begin{tabular}{lcccccccc}
\hline Patient No. & 1 & 2 & 3 & 4 & 5 & 6 & 7 & 8 \\
Age/sex & $76 / \mathrm{M}$. & $73 / \mathrm{M}$. & $85 / \mathrm{F}$. & $79 / \mathrm{F}$. & $78 / \mathrm{F}$. & $77 / \mathrm{F}$. & $85 / \mathrm{M}$. & $81 / \mathrm{F}$. \\
\hline Preop uncorr. & $\mathrm{J} 13$ & $\mathrm{~J} 16$ & $\mathrm{~J} 8$ & $\mathrm{~J} 13$ & $\mathrm{~J} 13$ & $\mathrm{~J} 14$ & $\mathrm{~J} 13$ & $\mathrm{~J} 13$ \\
Preop with $+6,0$ & $\mathrm{~J} 1$ & $\mathrm{~J} 2$ & $\mathrm{~J} 1$ & $\mathrm{~J} 2$ & $\mathrm{~J} 5$ & $\mathrm{~J} 1$ & $\mathrm{~J} 1$ & $\mathrm{~J} 4$ \\
1D postop & $\mathrm{J} 6$ & $\mathrm{~J} 12$ & $\mathrm{~J} 13$ & $\mathrm{~J} 8$ & $\mathrm{~J} 1$ & $\mathrm{~J} 1$ & $\mathrm{~J} 13$ & $\mathrm{~J} 8$ \\
1W postop & $\mathrm{J} 1$ & $\mathrm{~J} 6$ & $\mathrm{~J} 1$ & $\mathrm{~J} 8$ & $\mathrm{~J} 2$ & $\mathrm{~J} 1$ & $\mathrm{~J} 1$ & $\mathrm{~J} 6$ \\
1M postop & $\mathrm{J} 2$ & $\mathrm{~J} 5$ & $\mathrm{~J} 1$ & $\mathrm{~J} 2$ & $\mathrm{~J} 1$ & $\mathrm{~J} 1$ & $\mathrm{~J} 1$ & $\mathrm{~J} 7$ \\
3M postop & $\mathrm{J} 7$ & $\mathrm{~J} 6$ & $\mathrm{~J} 2$ & $\mathrm{~J} 3$ & $\mathrm{~J} 6$ & $\mathrm{~J} 1$ & $\mathrm{~J} 3$ & $\mathrm{~J} 8$ \\
6M postop & - & $\mathrm{J} 2$ & $\mathrm{~J} 4$ & $\mathrm{~J} 3$ & $\mathrm{~J} 8$ & $\mathrm{~J} 1$ & $\mathrm{~J} 3$ & $\mathrm{~J} 8$ \\
\hline
\end{tabular}

D - day, W - week, M - month(s), M. - male, F. - female, J. - Jaeger, preop - preoperatively, postop - postoperatively

three months after surgery the mean IOP was $14 \mathrm{~mm}$ $\mathrm{Hg}$ (11-19 $\mathrm{mmHg}$ ) and remained unchanged six months postoperatively. There were no problems with corneal decompensation after implantation.

At the baseline, the mean central retinal thickness (CRT) (minimum-maximum values) measured with optical coherence tomography (OCT) was 165 um (115-256 um). In all but two patients, there was dry AMD- geographic atrophy. In one patient (patient No. 1) there were soft drusen, and in patient No. 8, there was a stabilized wet form of AMD. One month after SML implantation, the mean CRT was 182 um (166-211), three months postoperatively 197 um (120-338), and after six months it was 176 um (110-212 um).

There were no reported adverse events during the postoperative period except for one. Of the eight patients with SML, one (patient No. 1) converted to wet AMD, three months post-implantation, VA 0.1 and was unable to read. The conversion was diagnosed early and the patient underwent anti-VEGF therapy (ranibizumab) with stabilization of vision. No development of a secondary cataract or any other opacification between the two intraocular lenses was found.

\section{DISCUSSION}

Reading is one of the most frequently performed psycho-physiological operations and requires cooperation between the oculomotor system (miosis-convergence-accommodation- eye tracking) and the visual system (optical media of the eye, retina) and interpreting processes in the brain. Age-related macular degeneration is the most common cause of loss of reading vision among patients older than 55 years ${ }^{7}$. All of the participants of this study suffered from AMD.

Low vision aids can be divided into two categories according to their function: those that translate visual information into alternative sensory information, such as sound or touch (sensory substitution); and those that adapt visual information to render it more visible to the user, for example through magnification ${ }^{8}$. Several external magnifying low visual aids, amplifying the image to be recognizable by perimacular receptive fields of the retina, are available on the market.Loss of field of vision, a short reading distance, the weight and large size of the aid are the most common problems associated with these aids ${ }^{9}$. Some can be surmounted using an internalized telescope implanted in the anterior segment of the eye $\mathrm{e}^{5,9-12}$.

The purpose of this study was to present the initial experience with a new intraocular implant - the Scharioth Macula Lens. The SML was first implanted in September 2013 by Gabor B. Scharioth. The implant is designed for sulcus fixation in pseudophakic eyes to increase uncorrected near visual acuity (UNVA) in patients with stabilized maculopathy. It provides sufficient magnification of 2-3 times; the total magnification depends on the anatomy of the eye and the final reading distance ${ }^{5}$. The effect of SML is based on so-called Near Triad Reflex: miosis, accommodation, convergence. Due to the effect of near vision miosis, the central optical portion providing the magnified image will dominate when the patient focusses on near objects. Miosis is accentuated with light and this was also observed by the participants in our study, reading was better under very good light conditions. Distance vision was not influenced by dilated pupils.

Low vision patients using visual aids are required to use head or hand movements more often than natural eye movements to scan the text, which results in vestibularocular conflict and discomfort ${ }^{1,13}$. Images provided by magnifying devices are different from images the patients were used to seeing with healthy eyes. This, together with the different reading techniques required to be used with visual aids, is the reason why many older visually impaired adults have difficulty getting used to a new device. Patient motivation and daily reading exercises are of the utmost importance for achieving the best results and satisfied patients, also in the case of patients with SML in our experience.

Our experience with eight patients to date has been very favorable. Apart from one, all of the patients in the study with the SML, acquired good near visual acuity at a recommended reading distance of $15 \mathrm{~cm}$, without compromising distance vision. The SML implantation is feasible for standard cataract surgery and is tolerated by patients. It does not disturb retinal examination including OCT, which is important for diagnosing and monitoring macular or optic nerve disc diseases ${ }^{14,15}$. Posterior capsule opacification (PCO) is one of the most common complications of cataract extraction with an intraocular 
lens (IOL) implantation. Other opacifications of IOLs or on the interlenticular surface can also be observed in the case of piggy bag IOL implantations ${ }^{16}$. No development of vision disturbing secondary cataract or any other opacification between the two intraocular lenses was found in any of the participants in this study.

The follow-up of the patients implanted with the SML is ongoing. They will be examined after one year and then every six months post implantation. Our department is also participating in an ongoing multicentric study, the initial results of which will be published soon.

The prospects of reading rehabilitation after SML implantation are promising; despite the very severe findings in the macula, the SML enables the patients involved in our study to read again and their quality of life has improved.

\section{CONCLUSION}

The Scharioth Macula Lens is a new hope for lowvision patients, it acts as a magnifier in the eye. It is a suitable method for increasing near visual acuity in patients with maculopathy. Based on our experience, careful preoperative examination, good indication and realistic patient expectations and cooperation are crucial for the optimal outcome. The prospects for reading rehabilitation after SML implantation are more than promising.

Acknowledgement: Financial interest: This work was financially supported by the project of Charles University PROGRES Q40/07.

Author contribution: All authors contributed equally to preparing the manuscript.

Conflict of interest statement: The authors state that there are no conflicts of interest regarding the publication of this article.

\section{REFERENCES}

1. Singer MA, Amir N, Herro A, Porbandarwalla SS, Pollard J. Improving quality of life in patients with end-stage age-related macular de- generation: focus on miniature ocular implants. Clin Ophthalmol 2012;6:33-9.

2. van der Aa HP, van Rens GH, Comijs HC, Margrain TH, Gallindo-Garre F, Twisk JW, van Nispen RM. Stepped care for depression and anxiety in visually impaired older adults: multicentre randomised controlled trial. BMJ 2015;351(23):h6127.

3. Kremláček J, Jirásková N, Nekolová J, Šikl R, Kuba M. Electrophysiological testing of visual function after mirror telescope implantation: a case report. Doc Ophthalmol 2016;133:171-81. doi:10.1007/ s10633-016-9563-9

4. Hooper P, Jutai JW, Strong G, Russell-Minda E. Age related macular degeneration and low-vision rehabilitation: a systematic review. Can J Ophthalmol 2008;43:180-7.

5. Scharioth GB. New add-on intraocular lens for patients with agerelated macular degeneration. J Cataract Refract Surg 2015;41:155963.

6. Blesi M, Wise B, Kelley-Arney C. Medical Assisting Administrative and Clinical Competencies. Cengage Learning; 2011. p. 888-90.

7. Rencová $E$, Bláha $M$, Studnička J, Bláha, V, Lánská $M$, Renc O, Stepanov A, Kratochvílová V, Langrová H. Preservation of the Photoreceptor Inner/Outer Segment Junction in Dry Age-Related Macular Degeneration Treated by Rheohemapheresis. J Ophthalmol 2015 (2015), article ID 359747

8. Moshtael H, Aslam T, Underwood I, Dhillon B. High Tech Aids Low Vision: A Review of Image Processing for the Visually Impaired. Tran Vis Sci Tech 2015;4(4):6.

9. Agarwal A, Lipshitz I, Jacob S, Lamba M, Tiwari R, Kumar DA, Agarwal A. Mirror telescopic intraocular lens for age-related macular degeneration. Design and preliminary clinical results of the Lipshitz macular implant. J Cataract Refract Surg 2008;34:87-94.

10. Brown GC, Brown MM, Lieske HB, Lieske PA, Brown KS, Lane SS. Comparative effectiveness and cost- effectiveness of the implantable miniature telescope. Ophthalmology 2011;118(9):1834-43.

11. Boyer D, Freund KB, Regillo C, Levy MH, Garg S. Long-term (60-month) results for the implantable miniature telescope: efficacy and safety outcomes stratified by age in patiens with end-stage agerelated macular degeneration. Clin Ophthalmol 2015;9:1099-107.

12. Hudson HL, Stulting RD, Heier JS, Lane SS, Chang DF, Singerman LJ, Bradford CA, Leonard RE. Implantable telescope for end-stage agerelated macular degeneration: long-term visual acuity and safety outcomes. Am J Ophthalmol 2008;146(5):664-73.

13. Qureshi MA, Robbie SJ, Tabernero J, Artal P. Injectable intraocular telescope: Pilot study. J Cataract Refract Surg 2015;41:2125-35.

14. Hejsek L, Dusova J, Stepanov A, Rozsival P. Re-operation of idiopathicmacular hole after failed initial surgery. Biomed Pap Med Fac Univ PalackyOlomouc Czech Repub 2014;158(4):596-9.

15. Hejsek L, Kana V, Rozsival P, Dusová J, Stepanov A, Trávníček P, Tuček I. Total Avulsion of the Eye Globe Combined with an Injury of the Chiasm - a Case Report. Cesk Slov Neurol N 2014;77/110(4):510-14.

16. Werner L1, Shugar JK, Apple DJ, Pandey SK, Escobar-Gomez M, Visessook N, Evans BB. Opacification of piggyback IOLs associated with an amorphous material attached to interlenticular surfaces.J Cataract Refract Surg 2000;26:1612-9. 